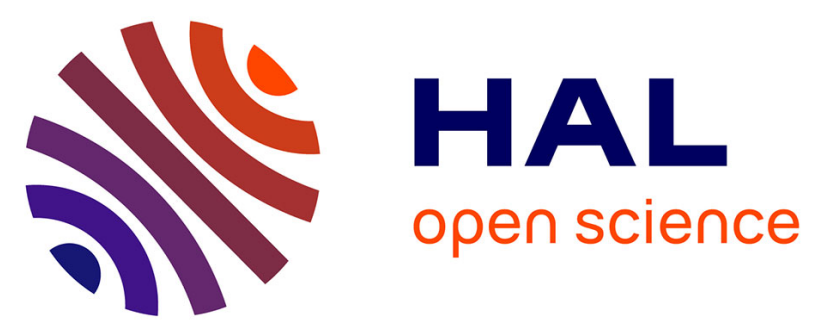

\title{
Experimental charge density evidence for the existence of high polarizability of the electron density of the free electron pairs on the sulfur atom of the thioureido group, NH-C(S)-NH2, induced by $\mathrm{N}-\mathrm{H}$ center dot center $\operatorname{dot} \mathrm{S}$ and $\mathrm{C}-\mathrm{H}$ center $\operatorname{dot}$ center $\operatorname{dot} \mathrm{S}$ interactions
} Sladjana Novakovic, Bernard Fraisse, Goran A. Bogdanović, Anne Spasojevic - de Biré

\section{- To cite this version:}

Sladjana Novakovic, Bernard Fraisse, Goran A. Bogdanović, Anne Spasojevic - de Biré. Experimental charge density evidence for the existence of high polarizability of the electron density of the free electron pairs on the sulfur atom of the thioureido group, $\mathrm{NH}-\mathrm{C}(\mathrm{S})-\mathrm{NH} 2$, induced by $\mathrm{N}-\mathrm{H}$ center dot center dot S and C-H center dot center dot S interactions. Crystal Growth \& Design, 2007,7 (2), pp.191-195. 10.1021/cg060497+ . hal-00142345

\author{
HAL Id: hal-00142345 \\ https://hal.science/hal-00142345
}

Submitted on 29 Sep 2020

HAL is a multi-disciplinary open access archive for the deposit and dissemination of scientific research documents, whether they are published or not. The documents may come from teaching and research institutions in France or abroad, or from public or private research centers.
L'archive ouverte pluridisciplinaire HAL, est destinée au dépôt et à la diffusion de documents scientifiques de niveau recherche, publiés ou non, émanant des établissements d'enseignement et de recherche français ou étrangers, des laboratoires publics ou privés. 


\title{
Experimental charge density evidence for high
}

\section{polarizability of the electron density of the free electron}

\author{
pairs on the sulfur atom of the thioureido group,
}

-NH-C(=S)-NH 2 , induced by N-H...S and C-H...S

interactions

Sladjana B. Novaković, Bernard Fraisse, Goran A. Bogdanović*, Anne Spasojević-de Biré*

"VINČA" Institute of Nuclear Sciences, Laboratory of Theoretical Physics and Condensed Matter

Physics, PO Box 522, 11001 Belgrade, Serbia

Laboratoire "Structures Propriétés et Modélisation des Solides", UMR 8580 du CNRS, Ecole Centrale

Paris, 92295 Châtenay-Malabry, France

* Corresponding Author E-mail Address:

goranb@vin.bg.ac.yu; anne.spasojevic@ecp.fr 
Abstract

The experimental charge density study of salicylaldehyde thiosemicarbazone (SalTSC) has been performed. The analysis of the crystal packing revealed that the sulfur atom is simultaneously engaged in six hydrogen bonding interactions, two of N-H...S, leading to a dimmer, and four of CH...S type. It has been established that the deformation density of the free electron pairs on the sulfur atom is inhomogeneously distributed within a torus. A relationship found between the deformation of the torus and the space directionality of the surrounding donor groups suggests that the sulfur atom of the thioureide moiety easily adjusts to the environment in order to increase the number of stabilizing contacts. CSD study of the compounds containing thioureido $-\mathrm{N}-\mathrm{C}(=\mathrm{S})-\mathrm{N}$ fragment confirmed the experimental results for SalTSC, i.e. about $60 \%$ of the analyzed crystal structures form dimer trough NH...S interactions while in about $50 \%$ of crystal structures the $\mathrm{S}$ atom forms four of more D-H...S intermolecular interactions $(\mathrm{D}=\mathrm{C}, \mathrm{N}$ and $\mathrm{O})$. 
Recent investigations in the field of supramolecular chemistry have revealed the complex nature of supramolecular organizations and emphasized the role of the weak associative forces in the structure stabilization ${ }^{1}$. In that context, hydrogen bonding involving sulfur atom, although generally ranked as weak, take a significant place among the stabilizing factors ${ }^{2}$. It is well known that $\mathrm{S}$ atom exhibits much weaker acceptor abilities compared to the atoms with more compact negative charge such as $\mathrm{O}$ and $\mathrm{N}$; however several experimental charge density studies have confirmed that $\mathrm{S}$ atom can also serve as an acceptor for very weak donors such as $\mathrm{C}-\mathrm{H}$ groups ${ }^{3}$. These conclusions have been made on the basis of Bader's topological analysis of the electron density, which is a trusted and widely used indicator of the existence of molecular interactions ${ }^{4}$. High-resolution diffraction data combined with multipole refinements have proven to be the most precise experimental method for the analysis of molecular structures at the electronic level ${ }^{5}$. However, in the case of sulfur-containing compounds, which are generally less frequent in experimental charge density literature ${ }^{3,6}$, treatment of the $S$ atom has been rather problematic in the majority of cases. Thus, information about the deformation electron density of $\mathrm{S}$ atom are less reliable since the residual charge density map in the vicinity of the $\mathrm{S}$ atom showed significant residuals features.

In the present work, a very high quality data obtained by high resolution, low temperature charge density study of salicylaldehyde thiosemicarbazone (SalTSC) ${ }^{7,8}$, allowed us to precisely analyze via a multipole refinement ${ }^{9}$ the electronic features of the $\mathrm{S}$ atom and to provide some additional insights into the acceptor abilities of this atom and the nature of the corresponding interactions at the electronic level. The multipole refinement ${ }^{9}$ based on Hansen and Coppens model was performed using two different software, Molly ${ }^{10 a}$ and $\mathrm{XD}^{10 \mathrm{~b}}$.

It is important to mention that in thioureido based compounds $\left(-\mathrm{NH}-\mathrm{C}(=\mathrm{S})-\mathrm{NH}_{2}\right)$, and SalTSC can be considered as one of them, the resonance effect which includes two nitrogen atoms, N2 and N3, and the $\mathrm{C}=\mathrm{S}$ bond (Fig. 1) considerably increases the amount of negative charge on the $\mathrm{S}$ atom and, hence, its acceptor abilities ${ }^{11}$. The analysis of the packing arrangement of SalTSC and topology of the 
experimental electron density have shown that in this case the $\mathrm{S}$ atom is simultaneously engaged in six hydrogen bonding interactions, the two of N-H..S type and four of C-H...S type (Supporting information, Fig. S1). Topological analysis confirmed for both multipole refinements, XD and Molly (Table 1.), the existence of BCP for all six interactions ${ }^{12,13}$. To the best of our knowledge, the simultaneous involvement of an acceptor atom in a six different hydrogen interactions, represents a rare phenomenon. It also suggests that the entity with such capabilities could play an important role in the stabilization of the system of interest. To provide more accurate distinction between these interactions we compare their influence on the valence electron density of the $S$ atom.

The deformation electron density ${ }^{14}$ of the valence electrons of the $\mathrm{S}$ atom which are not engaged in covalent bonds is symmetrically distributed around the $\mathrm{S}$ atom and has the shape of a torus, with torus's axes placed along the C1-S direction, Fig. 2. For a more quantitative description of the arrangement of the electron density (ED) within the torus, we divided it by three mutually perpendicular planes and analyzed the ED in each of them (Fig. 2a). This approach revealed a quite inhomogeneous distribution of ED within the sulfur's torus, which probably originated from the influence of the above mentioned interactions. To explore this possibility we tried to find the relationship between the space directionality of the six interactions and the distribution of the deformation ED within the torus.

Analysis of the ED of a torus in the plane $\delta 1$ (Fig. 2b) shows that the torus is deformed toward the direction of all interactions, thus forming four bulges extending towards the $\mathrm{H}$ atoms of the surrounding donor's groups. Quantitative analysis of the torus's ED reveals pronounced accumulation of the ED toward three of the six interactions: N2-H2n...S1, N3-H3a...S1 and C7-H7 ..S1 (Fig. 2a and Fig. 3). More careful inspection however indicates that the polarization of the ED is more pronounced toward the weak C7-H7 donor.

Although the N2-H2n group forms the strongest interaction with the S atom, the highest concentration of the electron density in the sulfur's torus is actuality directed toward the $\mathrm{H} 7$ atom 
attached to C7 (Figs. 2b and 4c). Such a distribution of the highest density could be explained by the counter effect of the N3-H3a group which forms a hydrogen bond on the opposite side of the torus, relative to $\mathrm{N} 2-\mathrm{H} 2 \mathrm{n} . . \mathrm{S} 1$ interaction, Figs. $2 \mathrm{~b}$ and $4 \mathrm{a}$. It seems that this diametrally opposite N3H3a...S1 interaction reduces the extent of the torus polarization toward the N2-H2n...S1 (Fig. 4a). However, since the N2-H2n...S1 hydrogen bond is stronger than the N3-H3a...S1 one (Table 1), partial polarization still occurs in the N2-H2n direction (0.80 comparing to 0.70 e. $\left.\AA^{-3}\right)$, Fig. $4 \mathrm{a}$. Unexpectedly, the highest polarization occurs in the direction of the C7-H7 group (Figs. 2c and 4c) which forms, as already mentioned, a weak C7-H7...S1 interaction. Deformation electron density between S1 and H7 is more than two times higher than that on the opposite side of the torus (0.85 comparing to 0.35 e. $\left.\AA^{-3}\right)$ (Fig. 4c) and is quantitatively very similar to that observed between H2n and S1 $\left(0.80\right.$ e. $\left.\AA^{-3}\right)$, even though N2-H2n...S1 is a much stronger intermolecular interaction, Table 1.

The fact that the weak $\mathrm{C} 7-\mathrm{H} 7$ donor induces the highest polarization of the torus is in accordance with the other electrostatic properties of the SalTSC molecule. Namely, as obtained by integration over the atomic basins $s^{4,12}$ the $\mathrm{C} 7-\mathrm{H} 7$ group is carrying a significant positive charge $(+0.41 \mathrm{e})$, and it also exhibits the highest positive electrostatic potential (EP) on the molecule surface. On the contrary, the $\mathrm{S}$ atom is quite negatively charged $\left(-0.38\right.$ e from atomic basins $\left.{ }^{4,12}\right)$ and the most negative EP on the molecule surface is in the vicinity of this atom. Since it is well known that the values of the electrostatic potential on the molecular surface can be a good criterion for the analysis of the intermolecular interactions ${ }^{15}$, it is interesting to notice that the minimum of this EP is shifted out of the torus axes and directed toward the weak C7-H7 donor (Fig. 5). In that way the most negative region of the EP on the molecular surface is directed toward the most positive one which exactly corresponds to the $\mathrm{C} 7-\mathrm{H} 7 \ldots \mathrm{S} 1$ interaction. In addition, the extent of the positive and negative three-dimensional isopotential surfaces (Fig. 6) indicates that above the molecule surface the C7-H7 group again shows the highest potential for the formation of the D-H...A interactions. 
According to all these observations it can be suggested that $\mathrm{C} 7-\mathrm{H} 7 \ldots \mathrm{S} 1$ interaction stands out in its strength comparing to the other three C-H...S interactions in this structure and plays, together with $\mathrm{N} 2-\mathrm{H} 2 \ldots \mathrm{S} 1$, a crucial role in the polarization of the $\mathrm{S}$ torus. It is also worth to notice that, despite a quite long distance of $\mathrm{N} 3-\mathrm{H} 3 \mathrm{a} . . . \mathrm{S} 1$ interaction, the presence of the $\mathrm{BCP}$ and the polarization of the S torus which this interaction induces, suggest that this interaction and similar to it should not be neglected only on the basis of their geometrical parameters. According to Koch-Popelier (KP) criteria ${ }^{17}$, all other interactions, except the standard N2-H...S1 hydrogen bond, should be classified as van der Waals interactions since they do not fulfill the forth criterion concerning the mutual penetration of the van der Waals spheres. However, all interactions observed here, follow very closely the overall dependences of the KP criteria vs. bond path lengths $\left(\mathrm{R}_{\mathrm{ij}}\right)$ reported by Munshi and Row ${ }^{18}$ for the interactions of different strength.

Some theoretical studies have pointed out that the electrostatic potential at nuclear sites (EPN) represents a useful tool for the analysis of intermolecular interactions ${ }^{19}$. This parameter provides relevant information concerning the ability of hydrogen atoms to form hydrogen bonds and can also be useful for the clarification of the mechanisms of the aminolisys of some esters ${ }^{19}$. Therefore, we have determined the EPN values for each atom in the SalTSC molecule on the basis of our experimental data $^{20}$. The results are in accordance with the EP on the molecular surface emphasizing the significance of the C7-H7 group as a very potential donor since it exhibits the highest values of the EPN relative to other donors and their $\mathrm{H}$ atoms (Table 2). This study is the first example of the use of EPN criteria derived from an experimental charge density study.

As the topological analysis of ED has shown, the N2-H2n...S1 is the only interaction among the six observed D-H...S which can be classified as classical hydrogen bond. The formation of the N2H2n...S1 dimers (Fig. S8b) through this cyclic hydrogen bond represents the important structural motif for thioureido compounds which are entering the supramolecular structures ${ }^{21}$. To analyze the properties of this hydrogen bond in more details we extracted from $\mathrm{CSD}^{22}$ all structures containing the thioureido 
fragment (scheme I) and fulfilling the following criteria: crystallographic R-factor less than 0.075, errorfree coordinates (according to CSD checking criteria) and no disorder or polymerisation. All hydrogenatom positions determined from X-ray data were normalized to the standard neutron-derived bond distance $(1.08,1.02$ and $0.95 \AA$ for $\mathrm{C}-\mathrm{H}, \mathrm{N}-\mathrm{H}$ and $\mathrm{O}-\mathrm{H}$ groups respectively) along the $\mathrm{D}-\mathrm{H}$ bond vector derived from the X-ray results. Structures were retained only if the H...S distance $<3.1 \AA$.

It was found that from the 835 structures extracted, 495 contain the N-H...S dimer (Scheme II). The mean H...S distance was $2.46 \AA$ (Fig. S8a), which is similar to the distance found in the analysis of SalTSC. It is interesting to point out that all these dimer hydrogen bonds show similar geometry considering the position of the $\mathrm{H}$ atom which respect to the sulfur's torus. That can be understood by analyzing the C-H...S angle (Fig. 8a) which gives an average value of $108^{\circ}$ which is in good agreement with the experimental angle $\mathrm{C}-\mathrm{S}-\mathrm{Q}_{\max }$ (where $\varrho_{\max }$ is the maximum of the electron density in the torus) found in $\operatorname{SalTSC}\left(104^{\circ}\right)$.

The geometry of the dimer N-H...S interaction can be further examined by analysis of the angle between the vectors V1 (direction of the C-S bond) and V2 (direction of the N-H bond) (Scheme II). The diagram (Fig. 8b) shows that the preferable value is $116^{\circ}$, which is again in good agreeement with the experimental data of SalTSC.

Analysis of the displacement of the $\mathrm{H}$ atom (angle $\psi$ ) regarding the $-\mathrm{N}-\mathrm{C}(=\mathrm{S})-\mathrm{N}$ mean plane (Fig. 8c) suggests that, in a considerable number of structures, the $\mathrm{H}$ atoms involved in N-H...S interactions deviate significantly from the opposite $-\mathrm{N}-\mathrm{C}(=\mathrm{S})-\mathrm{N}$ plane which correlates with the distribution of ED in sulfurs torus. The broad distribution of $\psi$ suggests that the dimer N-H...S interactions are not localized only in $-\mathrm{N}-\mathrm{C}(=\mathrm{S})-\mathrm{N}$ planes but are often significantly displaced from it. This also suggests that the free electron density of the $\mathrm{S}$ atom is not localized in $-\mathrm{N}-\mathrm{C}(=\mathrm{S})-\mathrm{N}$ planes but distributed all over the torus as experimentally observed for SalTSC.

The analysis of the geometry of the 495 crystal structures suggests the existence of a torus shaped electron density in thioureide compounds which is the consequence of the increased amount of 
the electron density caused by the resonance effect spreading over this group. The high percent of the N-H..S dimer interactions in thioureide compounds (495 from 835 crystal structures) is particularly interesting considering that the CSD analysis of the equivalent ureide fragment, $(-\mathrm{N}-\mathrm{C}(=\mathrm{O})-\mathrm{N})$, resulted in a significantly lower percent of dimers (793 from 2320 structures). This result suggests that the thioureide molecules show higher tendency to form dimer N-H...S hydrogen bonds.

We also employed the CSD to analyze the ability of S atom from thioureido fragments to form multiple intermolecular interactions. We analyzed all interactions where the D-H...S interactions are shorter than $3.1 \AA$. (2077, 1430 and 123 for $\mathrm{C}-\mathrm{H}, \mathrm{N}-\mathrm{H}$ and $\mathrm{O}-\mathrm{H}$ donors). Almost all of the structures extracted from CSD form D-H...S interactions (821 from 835). What is particularly interesting is the fact that from 835 crystal structures with thioureido fragment 435 simultaneously form four or more DH...S interactions (279 form four, 135 form five and 40 form six or more.). Thus we can say that regardless of the strong dimer N-H...S hydrogen bonds which significantly influence the mutual orientation and crystal packing of thioureido-compound-molecules, the sulfur atoms from these molecules are able to simultaneously form several additional D-H...S intermolecular interactions. The geometry of these interactions was also examined and the results show that they also follow (although in a lesser extent) a spatial distribution which correspond to the torus shaped electron density of S atom. (Figs. 7 (a1-c1))

According to the results of the CSD analysis and also from the results of the experimental charge density of one of the molecule from the class of thioureide compounds it can be concluded that $\mathrm{S}$ atom from the thioureide moiety has a high capability to form multiple intermolecular interactions. This observations could be useful in the crystal engineering and design of supramolecular structures containing the thioureide $(\mathrm{NC}(\mathrm{S}) \mathrm{N})$ structural fragment.

Indeed, this $\mathrm{S}$ atom property should be taken into account in predictions and interpretations of the stabilization factors in the systems containing $\mathrm{S}$ atom and especially those including thioureide functionality $^{21}$. This study also emphasize the significance of the C-H...S interactions (particularly those 
with positively charged $\mathrm{C}-\mathrm{H}$ donor) which are often overlooked due to lack of directionality. This lack of directionality in C-H...S hydrogen bonds is understandable, considering that the torus of the sulfur atom could be equally polarized in any direction, which is not the case with the $\mathrm{O}$ atom which has a geometrically favorable orientation for $\mathrm{C}-\mathrm{H} \ldots \mathrm{O}$ hydrogen bond formation ${ }^{23}$. The simultaneous involvement of the $\mathrm{S}$ atom of SalTSC in six hydrogen interactions all over its torus which are also topologically confirmed, and the results of CSD analysis support the concept of the voluminous and easily polarizable sulfur atom ${ }^{24}$ as a stabilizing factor in supramolecular arrangements. 


\section{References}

(1) (a) Chopra, D.; Nagarajan, K.; Row, T. N. G. Cryst. Growth Des. 2005, 5, 1035-1039; (b)

Ghoshal, D.; Ghosh, A. K.; Ribas, J.; Zangrando, E.; Mostafa, G.; Maji, T. K.; Chaudhuri, N. R. Cryst. Growth Des. 2005, 5, 941-947; (c) Feng, Z.; Fan, A.; Valiyaveettil, S.; Vittal, J. J. Cryst. Growth Des. 2003, 1, 555-565; (d) Mallinson, P. R.; Smith, G. T.; Wilson, C. C.; Grech, E.; Wozniak, K. J. Am. Chem. Soc. 2003, 125, 4259-4270.

(2) (a) Krepps, M. K.; Parkin, S.; Atwood, D. A. Cryst. Growth Des. 2001, 1, 291-297; (b)

Potrzebowski, M. J.; Grossmann, G; Ganicz, K.; Olejniczak, S.; Ciesielski, W.; Kozio, A. E.; Wawrzycka, I.; Bujacz, G.; Haeberlen, U.; Schmitt, H. Chem. Eur. J. 2002, 8, 2691-2699; (c) Schiavo, S. L.; Nicolo, F.; Scopelliti, R.; Tresoldi, G.; Piraino, P. Inorg. Chim. Acta, 2000, 204, 108-113.

(3) (a) Destro, R.; Soave, R.; Barzaghi, M.; Presti L. L. Chem. Eur. J. 2005, 11, 4621-4634; (b) Munshi, P.; Thakur, T. S.; Row, T. N. G.; Desiraju R. G. Acta Cryst. 2006, B62, 118-127; (c) Munshi, P.; Row, T. N. G. Acta Cryst. 2006, B62, 612-626.

(4) Bader, R. F. W. Atoms in Molecules: a Quantum Theory, Clarendon Press: New York, 1990.

(5) (a) Coppens, P. X-ray charge density and chemical bonding; Oxford University press 1997.; (b) Coppens, P. Acta Cryst. 1998, A54, 779-788. (c) Koritsanszky, T. S.; Coppens, P. Chem. Rev. 2001, $101,1583-1628$.

(6) (a) Kutoglu, A.; Scheringer, C.; Meyer, H.; Schweig, A. Acta Cryst. 1982, B38, 2626-2632. (b) Cohen-Addad, C.; Lehmann, M. S.; Backer, P.; Davy H., Acta Cryst. 1988, B44, 522-527. (c) Wang, Y.; Chen, M. J.; Wu, C. H. Acta Cryst. 1988, B44, 179-182. (d) Wang, Y.; Chang, N. L.; Pai, C. T. Inorg. Chem. 1990, 29, 3256-3259. (e) Lin K. J.; Wang, Y. J . Phys. Chem. 1993, 97, 3176-3182. (f) Espinosa, E.; Molins, E.; Lecomte, C. ; Phys.Rev. 1997, B56, 1820-1833. (g) Dahaoui, S.; Pichon-Pesme, V.; 
Howard, J. A. K.; Lecomte, C. J.Phys Chem. 1999, 103, 6240-6250. (h) Scherer, W.; Spiegler, M.; Pedersen, B.; Tafipolsky, M.; Hieringer, W.; Reinhard, B.; Downs, A. J.; McGrady, G. S. Chem. Comm 2000, 635-636. (i) Pillet, S.; Souhassou, M.; Pontillon, Y.; Caneschi, A.; Gatteschi, D.; Lecomte. C. New J. Chem 2001, 25, 131-143. (j) Guillot, R.; Muzet, N.; Dahaoui, S.; Lecomte, C.; Jelsch, C. Acta Cryst. 2001, B57, 567-578. (k) Munshi, P.; Guru Row, T. N. Acta Cryst. 2002, B58, 1011-1017. (l) Hambley, T. W., Hibbs, D. E.; Turner, P.; Howardb, S. T.; Hursthouse M. B. J. Chem. Soc., Perkin Trans. 2002, 2, 235-239. (m) Hibbs, D. E.; Austin-Woods, C. J.; Platts, J. A.; Overgaard, J.; Turner P. Chem. Eur. J. 2003, 9, 1075-1084. (n) Lee, C. R.; Tang, T. H.; Chen, L.; Wang Y. Chem. Eur. J. 2003, 9, 3112-3121. (o) Ghermani, N. E.; Spasojević-de Biré, A.; Bouhmaida, N.; Ouharzoune, S.; Bouligand, J.; Layre, A.; Gref, R.; Couvreur, P. Pharm. Res., 2004, 21, 598-607. (p) Leusser, D.; Henn, J.; Kocher, N.; Stalke, D. J. Am. Chem. Soc. 2004, 126, 1871-1793. (q) Wagner, A.; Flaig, R.; Dittrich, B. ; Schmidt, H.; Koritsanszky, T.; Luger P. Chem. Eur. J. 2004, 10, 2977-2982. (r) Overgaard, J.; Hibbs D., E. Acta Cryst. 2004, B60, 480-487. (s) Wolstenholme, D. J.; Robertson, K. N.; Gonzalez, E. M.; Cameron, S. T, J. Phys. Chem. A 2006, 110, 12636-12643.

(7) Crystal data: chemical formula: C8H9N3OS, formula weight: 195.2, monoclinic, space group: C2/c, $a=13.9599(6), b=14.1007(5), c=10.4394(3) \AA, \beta=116.581(3)^{\circ}, V=1839.5(1) \AA^{3}, Z=8, \varrho_{c a l c}=1.38$ $\mathrm{g} \mathrm{cm}^{-3}, \mathrm{~T}=100(2) \mathrm{K}, \mu=0.29 \mathrm{~mm}^{-1}$, unique reflections $=9829$, observed reflections $[\mathrm{I}>3 \sigma(\mathrm{I})]=5459$, Npar $=488, \mathrm{R}[\mathrm{F}]=2.11 \%, \mathrm{Rw}[\mathrm{F}]=2.29 \%, \mathrm{GoF}=0.98$. More details about crystallographic parameters, data collection and reduction can be found in Supporting information, Table S1.

(8) Novaković, S. B.; Courcot, B.; Fraisse B.; Leovac V. M.; Bogdanović G. A., Spasojević-de Biré, A. in preparation.

(9) In order to obtain the model electron density we used the multipole pseudoatom model of Hansen and Coppens ${ }^{10 a}$. The refinement was first carried out with the program Molly ${ }^{10 a}$ and according to the 
residual density maps the refined model successfully described the electron density of Sal-TSC. Maximum contours in the residual maps in the vicinity of S1were within 0.05 e. $\AA^{-3}$ (see Supporting information for the residual density maps (Figs. S7) and the quantitative information concerning the residual electron density in the vicinity of $S$ atom). It is known however that the Molly program ${ }^{10 a}$ does not allow the introduction of separate $x^{\prime}$ parameters for the different $l$ values. Thus, to eliminate the possibility of an inadequate modeling of the electron density of the $\mathrm{S}$ atom, the refinement was also carried out with the XDLSM module incorporated in the XD software package ${ }^{10 b}$. Here the individual $x^{\prime}$ parameters were introduced for each of the $\mathrm{S}$ multipolar functions. Both refinements resulted in almost identical statistical descriptors and very similar residual density. The agreement of the positional, thermal, multipole as well as monopole charges parameters were within the estimated standard deviations. Since in the case of the XD refinement slightly higher residuals in the vicinity of S were observed the final results presented in this paper correspond to the multipole refinement obtained by the use of Molly. The tables presenting the complete results for both refinements are given as Supporting information, Table S1-S6.

(10) (a) Hansen, N. K.; Coppens, P. Acta Cryst. 1978, A34, 909-921. (b) Koritsanszky, T. S.; Howard, S.; Macchi, P.; Gatti, C.; Farrugia, L. J.; Mallinson, P. R.; Volkov, A.; Su, Z.; Richter, T.; Hansen, N. K. $\mathrm{XD}$, a computer program package for multipole refinement and analysis of electron densities from diffraction data; Free University of Berlin, Germany; University of Wales, Cardiff, UK.; Universita` di Milano, U.K.; CNR-ISTM, Milano, U.K.; University of Glasgow, U.K.; State University of New York, Buffalo, USA.; University of Nancy, France, 2003.

(11) Allen, F. H.; Bird, C. M.; Rowland, R. S.; Raithby, P. R. Acta Cryst. 1997, B53, 680-695.

(12) Souhassou, M.; Blessing, R. H. NEWPROP, J. Appl. Crystallogr. 1999, 32, 210-217. 
(13) A topological analysis was carried out with the NEWPROP ${ }^{12}$ (for the Molly results) and XDPROP (for the XD results) ${ }^{10 b}$. According to both analysis, the bond critical points for each of the six D-H...S interaction have been located. The sets of the topological parameters agree within the estimated standard deviations (Table S6). Fig. S3. in Supporting information depicts the Laplacian of the electron density and the position of the BCP in each of the six interactions.

(14) The deformation density is given as a difference between the total observed electron density and the calculated electron density of the promolecule define as the summation of spherical atom model densities. For more details see (5) and references therein.

(15) (a) Wozniak, K.; Mallinson, P. R.; Wilson, C. C.; Hovestreydt, E.; Grech, E. J. Phys. Chem. A. 2002, 106 6897-6903; (b) Bianchi, R.; Forni, A.; Pilati T. Acta Cryst 2004, B60, 559-568; (c) Wolstenholme, D. J.; Cameron, T. S. J. Phys. Chem. A 2006, 110, 8970-8978.

(16) Portmann, S.; Luthi, H. P. MOLEKEL: An Interactive Molecular Graphics Tool. Chimia 2000, $54,766-770$.

(17) Koch, U.; Popelier, P. L. A. J. Phys. Chem. 1995, 99, 9747-9754.

(18) Munshi P.; Row T. N. G. CrystEngComm, 2005, 7, 608-611.

(19) (a) Galabov, B.; Bobadova-Parvanova, P.; Ilieva; S.; Dimitrova, V. J. Molec. Struct. (Theochem) 2003, 630, 101-112 and references therein; (b) Ferrante F.; La Manna G. J. Phys. Chem. A 2003, 107, 91-96. (c) Galabov,B.; Cheshmedzhieva, D.; Ilieva, S. Hadjieva B. J. Phys. Chem. A, 2004, 108, 11457-11462. (d) Galabov, B., Atanasov, Y. Ilieva, S., Schaefer, H.F., J. Phys. Chem. A, 2005, 109, 11470-11474.

(20) Germani N. E. POTNUC, Locally written program for the determination of the electrostatic potential at nuclear sites on the basis of the experimentally determined charge density data. 
(21) (a) McBride, M. T.; Luo, T.-J. M.; Palmore, G. T. R. Cryst. Growth Des. 2001, 1, 39-46.

(b) Bourne, S. A.; Hallale, O.; Koch, K. R. Cryst. Growth Des. 2005, 5, 307-312. (c) Succaw, G. L.; Weakley, T. J. R.; Han, F.; Doxsee, K. M. Cryst. Growth Des. 2005, 5, 2288-2298.

(22) Allen, F. H. Acta Cryst. 2002, B58, 380.

(23) .Platts, J. A.; Howard, S.T.; Bracke, B.R.F., J. Am. Chem. Soc. 1996, 118, 2726-2733. (b) Bond, A. D.; Jones W. J. Chem. Soc., Dalton Trans., 2001, 3045-3051.

(24) (a) Borrmann, H.; Persson, I.; Sandström M.; Stålhandske C. M. V. J. Chem. Soc., Perkin Trans. 2000, 2, 393-402; (b) Wennmohs,F.; Staemmler, V.; Schindlera, M. J. Chem. Phys. $20031193208-$ 3218.

Acknowledgment . The authors would like to thank Prof. N.E. Ghermani (Laboratoire PPB, UMR 8510 CNRS - Paris XI, 92295 Châtenay-Malabry, France) for his encouragement and support for this work, especially for his suggestion to use EPN for the analysis of the intermolecular interactions. This work is as part of a project (co-directed by A. Spasojević-de Biré and G.A. Bogdanović) within the Franco-Serbian bilateral program "Pavle Savić 2006". S.B.N. and G.A.B thank the Ministry of Science and Environmental Protection of the Republic of Serbia for financial support (Projects Nos. 142028B and 142010B).

Supporting Information Available: Crystallographic experimental details, fractional coordinates and atomic thermal parameters, significant Gram-Charlier coefficients for anharmonic thermal motion of S atom, multipole population parameters; additional ORTEP projections, deformation and residual density maps of D-H...S interactions, and the quantitative information concerning the residual electron density in the vicinity of $\mathrm{S}$ atom, additional isodensity and isopotential surface representations of the electrostatic potential of SalTSC and C-H...S interaction, list of the refcodes for the crystal structure 
analyzed in CSD search. The deposition number of the supplementary crystallographic data is CCDC 606901. 


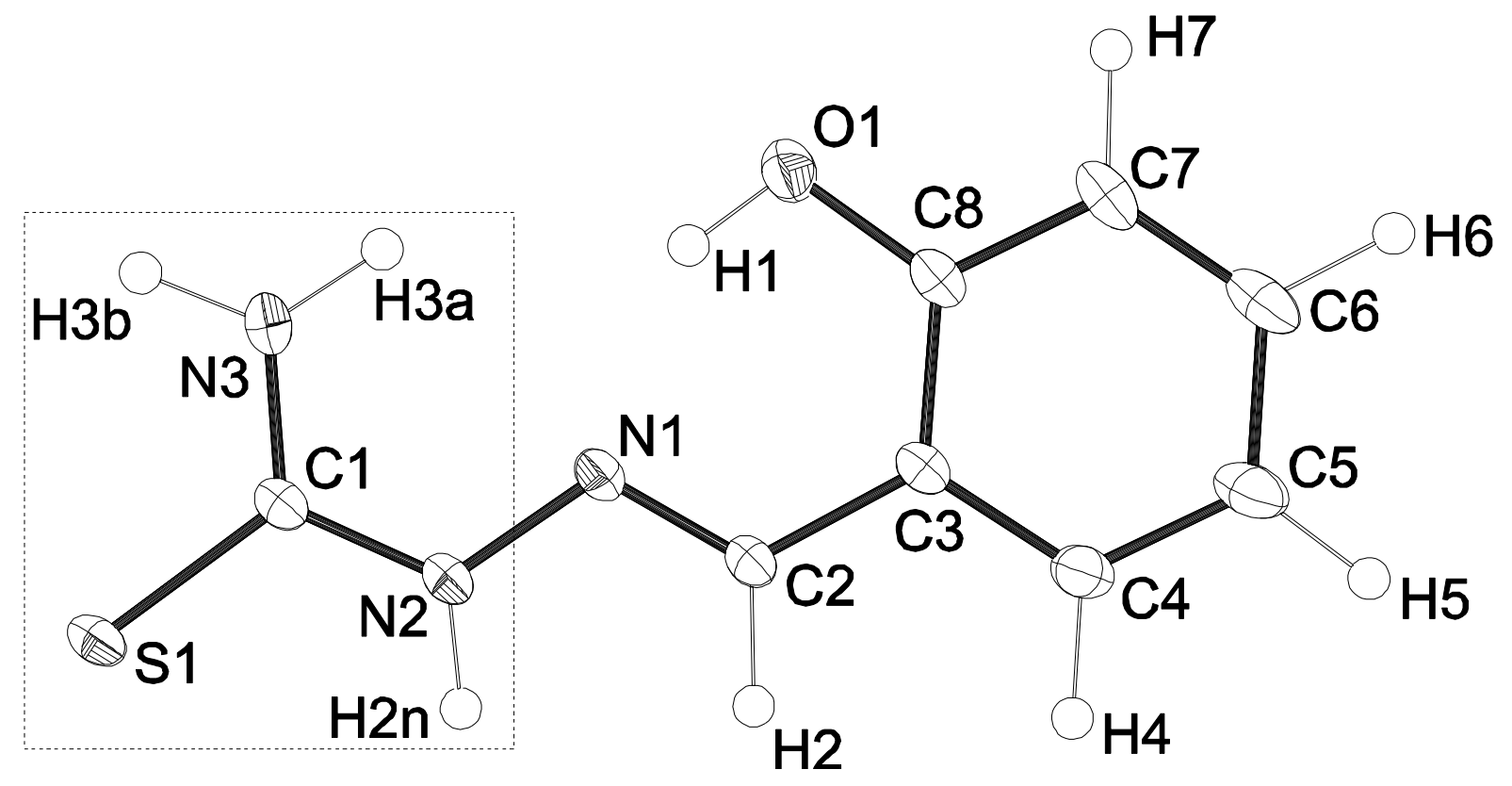

Figure 1. Crystal structure of SalTSC with atomic labeling scheme; thioureido moiety is indicated by the dashed frame. 


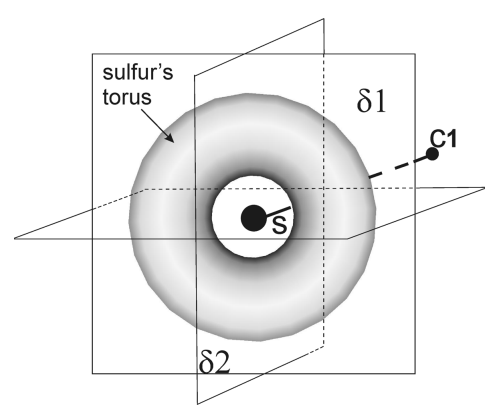

(a)

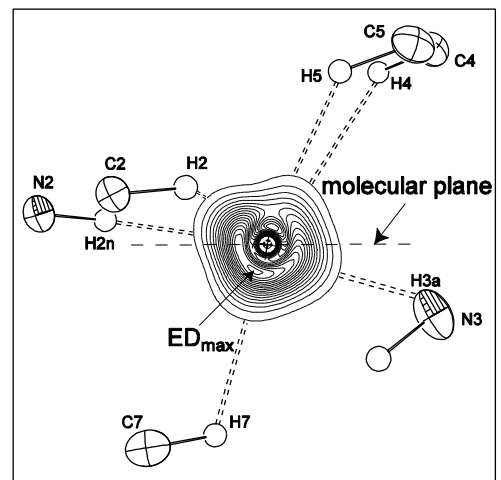

(b)

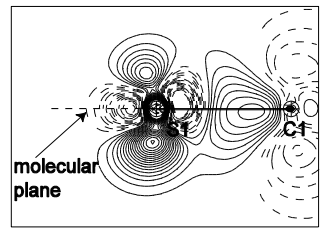

(c)

Figure 2. (a) Illustration of the torus shaped ED of the free electron pairs of the $\mathrm{S}$ atom divided by three orthogonal planes. (b) $\delta 1$ plane, deformation ED of the torus viewed down (along) the C1-S bond. (c) $\delta 2$ plane, deformation ED of the torus viewed orthogonally to the plane of SalTSC; the significant polarization observed below the molecular plane coincides with the position of the $\mathrm{C} 7-\mathrm{H} 7$ donor. 


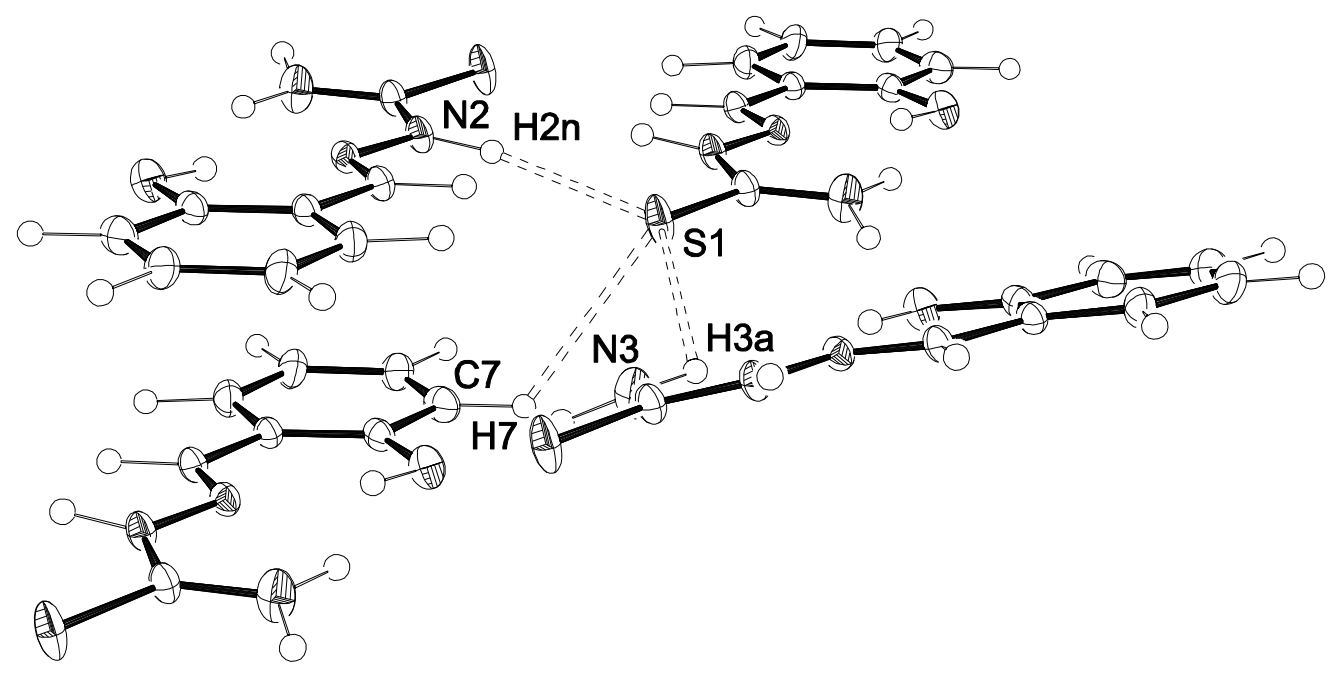

Figure 3. (a) D-H...S interactions which induce the highest polarization of the ED within the $S$ torus (additional projections, Fig. S2) 


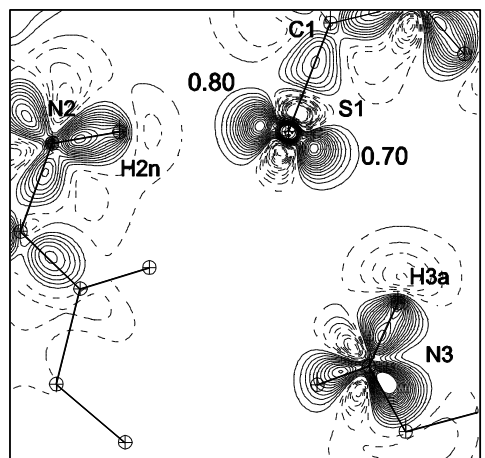

(a)

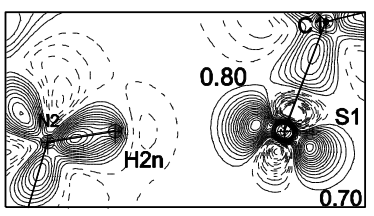

(b)

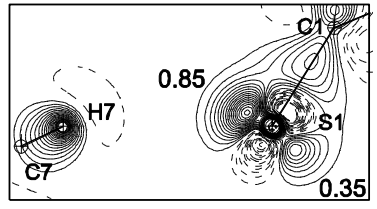

(c)

Figure 4. (a) Deformation ED in the H2n-S1-H3a plane showing both N-H...S interactions acting on the opposite sides of the sulfur's torus; polarization of the sulfur's torus by: (b) N2-H2n and (c) C7-H7 groups. In the aim of comparison the similar H...S1-C1 orientation plane was used for each interaction. (Contour at 0.05 e. $\AA^{-3}$; solid line indicates the accumulation, while the dashed line indicate the depletion of the ED in comparison with the isolated $\mathrm{S}$ atom). 


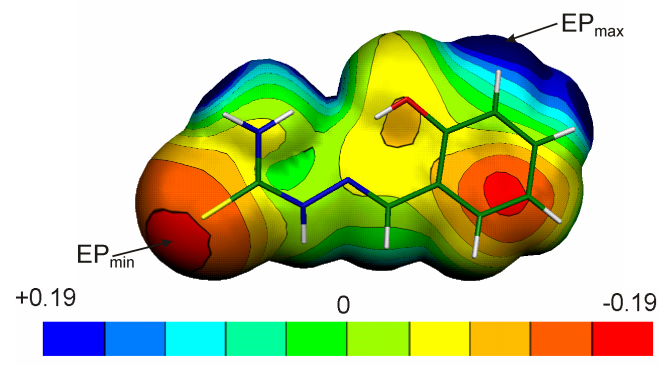

Figure 5. 3D isodensity surface $\left(0.007\right.$ e. $\left.\AA^{-3}\right)$ colored in accordance with the electrostatic potential ${ }^{16}$ (additional projections, Fig. S7). 


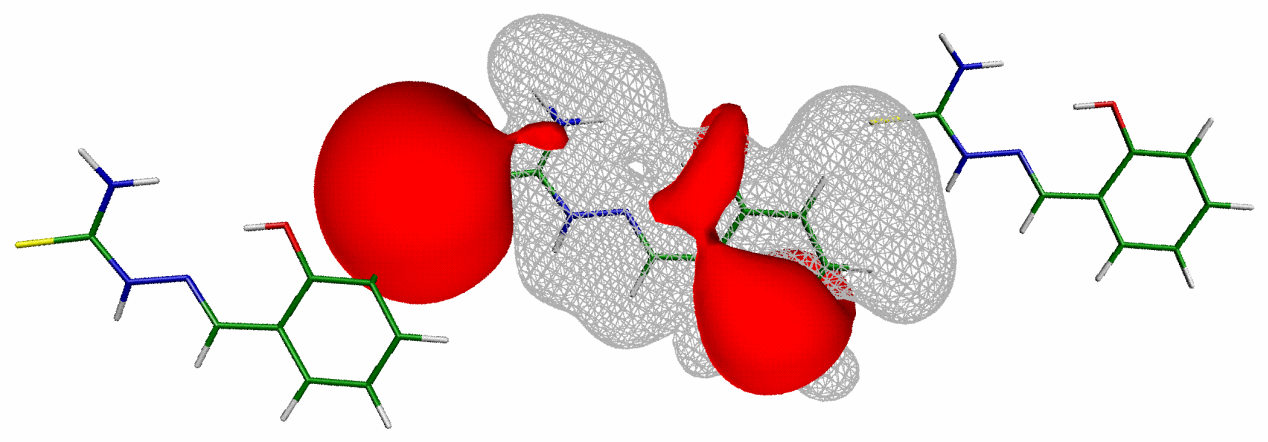

Figure 6. Isopotential surfaces around SalTSC molecule ${ }^{16}$. Grey and red correspond to +0.1 and -0.07 e. $\AA^{-1}$ respectively. The positive EP at $\mathrm{H} 7$ is emphasized toward the $\mathrm{S}$ atom while negative EP at $\mathrm{S}$ atom completely encompasses H7. 


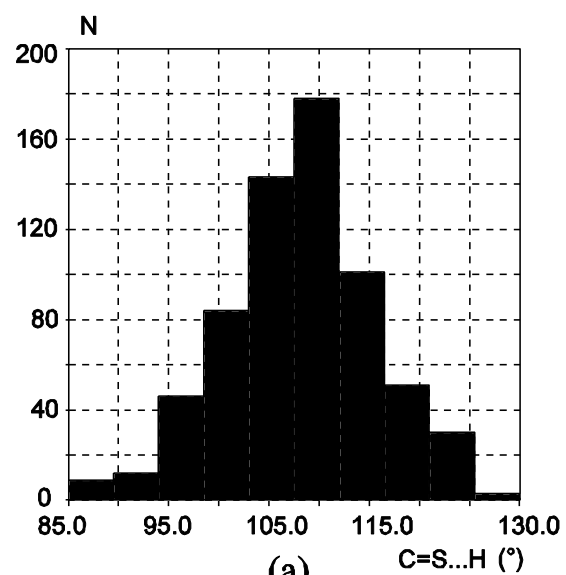

(a)

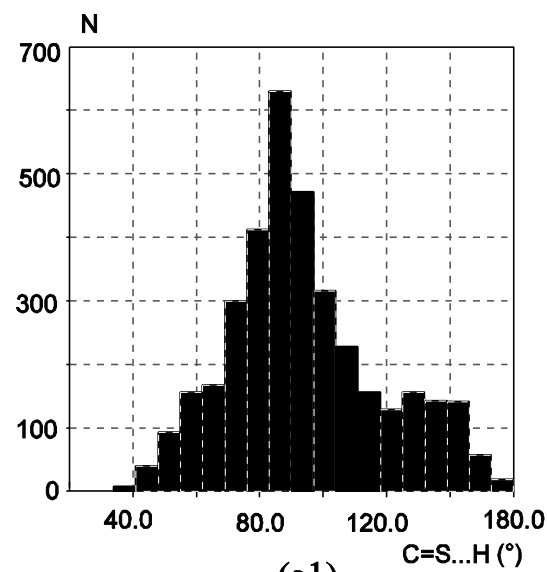

(a1)

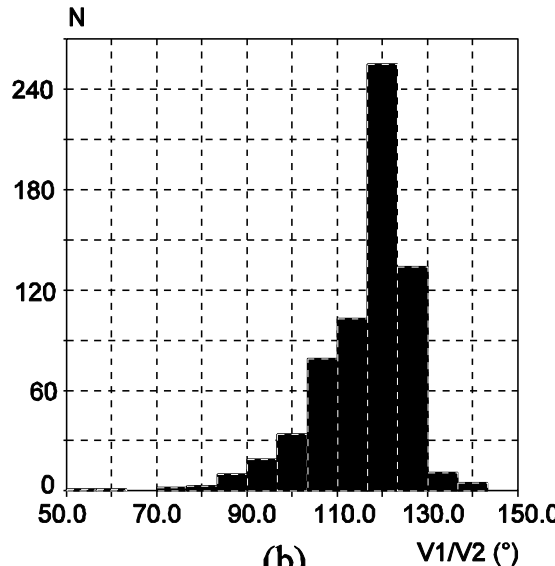

(b)

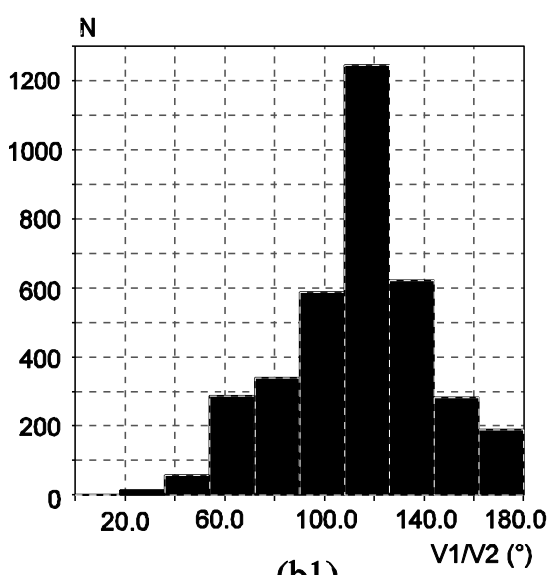

(b1)

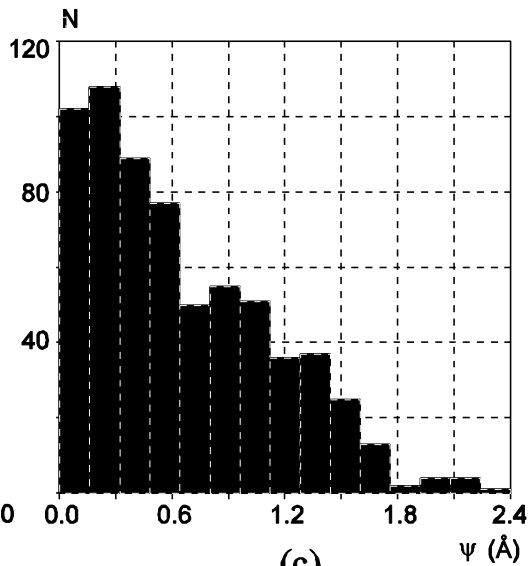

(c)

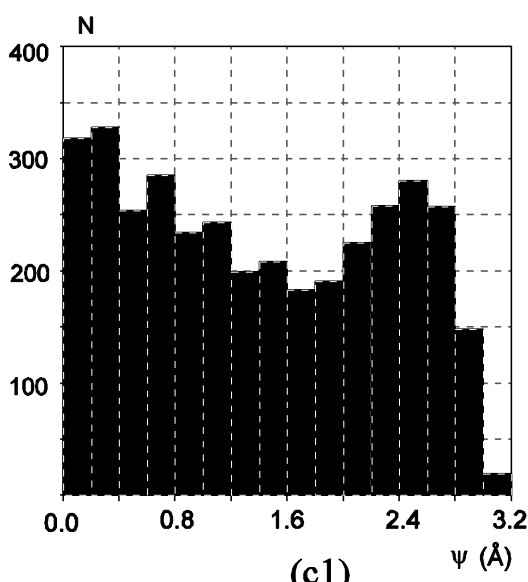

(c1)

Figure 7. Distribution of the geometrical parameters (analyzed in CSD) for the N-H...S dimer ( $a$, b and c) and D-H...S interactions (a1, b1 and c1). C-S...H is the angle between the approaching $\mathrm{H}$ atom and the $\mathrm{C}=\mathrm{S}$ bond; $\mathrm{v} 1 / \mathrm{v} 2$ is angle between the vectors directed along the $\mathrm{D}-\mathrm{H}$ and $\mathrm{C}=\mathrm{S}$ bonds; $\psi$ is displacement of the hydrogen atom from the $-\mathrm{N}-\mathrm{C}(=\mathrm{S})-\mathrm{N}$ plane. 
Table 1. Geometrical and topological ${ }^{a}$ proprieties of non-covalent interactions of S atom in Sal-TSc; $\delta$ angle is formed between the $\mathrm{S}$ atom, the maximum of the electron density in its torus directed toward the corresponding D-H...S interaction and the $\mathrm{H}$ atom. In five of six cases the $\delta$ is larger than conventional D-H...A angle showing the more favorable directionality of the D-H...S interactions when the torus shaped electron density is taken into account.

\begin{tabular}{|c|c|c|c|c|c|c|c|c|c|c|c|}
\hline Bond & $\begin{array}{l}\text { D-H } \\
(\AA)\end{array}$ & $\begin{array}{c}\text { H...A } \\
(\AA ̊)\end{array}$ & $\begin{array}{c}\text { D-H...A } \\
\left({ }^{\circ}\right)\end{array}$ & $\left({ }^{\circ}\right)$ & $\begin{array}{l}\text { d1 } \\
\text { (§̊) }\end{array}$ & $\begin{array}{l}\mathrm{d} 2 \\
(\AA \AA)\end{array}$ & $\begin{array}{l}\mathrm{Q}(\mathrm{r})_{\mathrm{bcp}} \\
\left(\mathrm{e} \AA^{-3}\right)\end{array}$ & $\begin{array}{c}\nabla^{2} \mathrm{Q}(\mathrm{r})_{\mathrm{bcp}} \\
\left(\mathrm{e} \AA^{-5}\right)\end{array}$ & $\mathrm{G}(\mathrm{r})_{\text {bcp }}$ & $V(r)_{\text {bcp }}$ & $\mathrm{H}(\mathrm{r})_{\mathrm{bcp}}$ \\
\hline $\mathrm{N} 2-\mathrm{H} 2 \mathrm{n} \ldots \mathrm{S} 1^{\mathrm{i}}$ & $0.99(2)$ & $2.438(10)$ & $170.04(5)$ & 171 & 0.852 & 1.586 & 0.09 & 1.25 & 28.30 & -22.62 & 5.69 \\
\hline $\mathrm{N} 3-\mathrm{H} 3 \mathrm{a} \ldots . . . \mathrm{S} 1^{\mathrm{ii}}$ & $1.00(4)$ & $2.924(10)$ & $122.87(7)$ & 153 & 1.153 & 1.868 & 0.03 & 0.42 & 852 & -5.62 & 2.90 \\
\hline $\mathrm{C} 2-\mathrm{H} 2 \ldots \mathrm{S} 1^{\mathrm{i}}$ & $1.06(4)$ & $2.948(9)$ & $139.26(6)$ & 90 & 1.199 & 1.823 & 0.04 & 0.48 & 10.16 & -7.27 & 2.88 \\
\hline $\mathrm{C} 4-\mathrm{H} 4 \ldots \mathrm{S} 1^{\mathrm{iii}}$ & $1.08(2)$ & $3.102(7)$ & $113.39(4)$ & 144 & 1.192 & 1.832 & 0.04 & 0.44 & 9.44 & -6.91 & 2.53 \\
\hline $\mathrm{C} 5-\mathrm{H} 5 \ldots . . . \mathrm{S} 1^{\mathrm{iii}}$ & $1.08(3)$ & $3.151(9)$ & $113.78(5)$ & 140 & 1.280 & 1.996 & 0.03 & 0.38 & 7.79 & -5.25 & 2.54 \\
\hline $\mathrm{C} 7-\mathrm{H} 7 \ldots \mathrm{S} 1^{\text {iv }}$ & $1.07(3)$ & $3.008(8)$ & $124.64(7)$ & 139 & 1.191 & 1.887 & 0.03 & 0.41 & 8.33 & -5.53 & 2.81 \\
\hline
\end{tabular}

Symmetry codes: (i) $1.5-\mathrm{x}, 0.5-\mathrm{y}, 1-\mathrm{z}$; (ii) $\mathrm{x}, 1-\mathrm{y}, 0.5+\mathrm{z}$; (iii) $1.5-\mathrm{x}, 0.5+\mathrm{y}, 0.5-\mathrm{z}$; (iv) x, y, z + 1 . ${ }^{a} \mathrm{~d} 1$ and $\mathrm{d} 2$ are the distances from the $\mathrm{BCP}$ to the $\mathrm{H}$ and $\mathrm{S}$ atoms respectively; $\mathrm{Q}(\mathrm{r})_{\mathrm{bcp}}$ is the electron density in BCP; $\nabla^{2} \mathrm{Q}(\mathrm{r})_{\mathrm{bcp}}$ is the Laplacian; $\mathrm{G}(\mathrm{r})_{\mathrm{bcp}}, \mathrm{V}(\mathrm{r})_{\mathrm{bcp}}$ and $\mathrm{H}(\mathrm{r})_{\mathrm{bcp}}$ are kinetic, potential and total energy density respectively, given in $\mathrm{kJ} \mathrm{mol}^{-1} \mathrm{bohr}^{-3}$ 
Table 2. Electrostatic potential at the atomic sites of SalTSC molecule (in atomic units)

\begin{tabular}{|l|r|}
\hline & EPN \\
\hline O1 & -22.403 \\
N1 & -18.500 \\
N2 & -18.433 \\
N3 & -18.456 \\
C1 & -14.752 \\
C2 & -14.857 \\
C3 & -14.934 \\
C4 & -15.018 \\
C5 & -15.184 \\
C6 & -15.006 \\
C7 & -14.677 \\
C8 & -14.856 \\
S1 & -59.617 \\
H1 & -1.012 \\
H2 & -1.031 \\
H2n & -0.989 \\
H3a & -0.933 \\
H3b & -1.043 \\
H4 & -1.197 \\
H5 & -1.159 \\
H6 & -1.016 \\
H7 & -0.842 \\
\hline
\end{tabular}



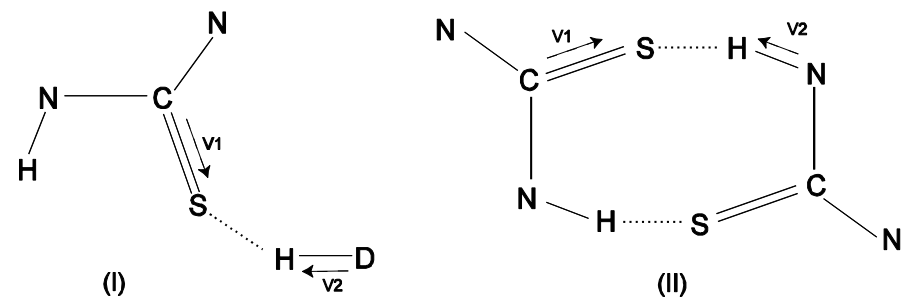

Scheme 1. Fragments used in CSD search 
TOC graphic

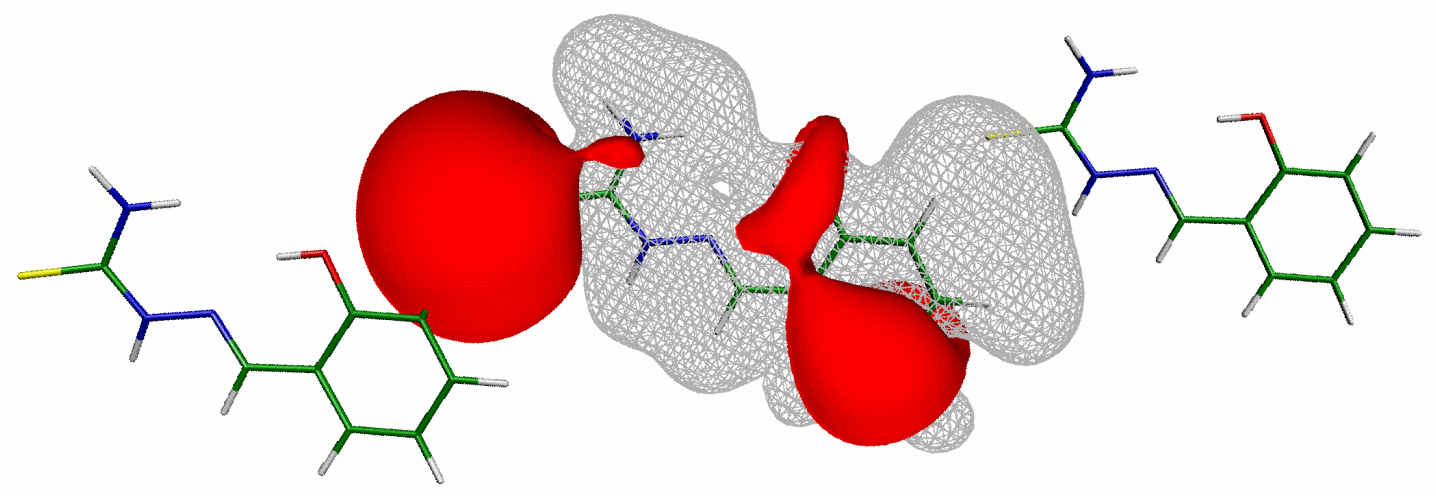

Synopsis

The torus shaped free electron pairs of the $\mathrm{S}$ atom from thioureide moiety easily adjust to the environment in an order to increase the number of stabilizing contacts. CSD search of the compounds which comprise $-\mathrm{N}-\mathrm{C}(=\mathrm{S})-\mathrm{N}$ fragment supports conclusions about the sulfur ability to form multiple DH...S interactions. 